\title{
Influence of Disulfide Bonds on the Conformation of the Antifungal Protein from Eucommia ulmoides Oliver
}

\author{
M. Jayanthi ${ }^{1}$, P. Kangueane ${ }^{1,3}$, N.A. Udaya Prakash ${ }^{2}$, D.V. Anupama Jigisha ${ }^{2}$ and K. Sekar ${ }^{*}, 2,4$ \\ ${ }^{I}$ School of Biotechnology, Chemical and Biomedical Engineering, VIT University, Vellore 632 014, India \\ ${ }^{2}$ Bioinformatics Centre, (Centre of excellence in Structural Biology and Bio-computing) \\ ${ }^{3}$ Biomedical Informatics, 17 A, Irulan Sandy Annex, Pondicherry 607 402, India \\ ${ }^{4}$ Supercomputer Education and Research Centre, Indian Institute of Science, Bangalore 560 012, India
}

\begin{abstract}
The three-dimensional structure of a cysteine rich antifungal protein EAFP2 is found to be compact and extremely stable. The rigid nature of the protein is attributed to the presence of five disulfide bonds. However, the effect of individual disulfide bonds on the conformation has not been characterized. Thus, Molecular Dynamics (MD) simulations are used to explicate the influence of disulfide bonds on the conformation. In the present study, the cysteine residues in the native structure are mutated to alanine and the structural characteristics and conformational dynamics of the native and mutant structures are analyzed to better understand the effect of disulfide bonds on the tertiary structure. The simulated native and single mutant structures are found to posses similar conformations, indicating that loss of disulfide bond did not affect the tertiary structure conformation greatly. However, in the single mutant (C7A) structure, the $\mathrm{N}$ and C-terminal segments are found to be different. It is also interesting to note that the loss of disulfide bond between Cys 35 and Cys 39 actually resulted in a more compact structure.
\end{abstract}

Keywords: Antifungal protein, molecular dynamics simulations, cysteine mutations.

\section{INTRODUCTION}

Disulfide bonds play a key role in the folding and stability of proteins [1-3]. Also, covalent bonds formed due to oxidation of cysteine residues act as switches for protein function [4] and regulation of enzymatic activity $[3,5]$. The disulfide-containing proteins are found to perform diverse functions such as cell-to-cell recognition, cell signaling and cell defense [6]. The highly specific nature of these interactions makes the cysteine-rich proteins suitable for the development of drugs and diagnostic agents [7,8]. Further, the disulfide bonds influence the local and global protein structural dynamics [9]. As stated in the literature, molecular dynamics (MD) simulation studies have elucidated the importance of disulfide bonds on the conformational dynamics of proteins $[10,11]$.

The antifungal protein (EAFP2) isolated from the bark of Eucommia ulmoides tree $[12,13]$ is composed of a $3{ }_{10}$-helix, a $\alpha$-helix and a three-stranded anti-parallel $\beta$-sheet (Fig. 1). The striking feature that distinguishes EAFP2 from other chitin-binding plant antifungal peptides is the presence of five disulfide bonds [Cys3-Cys17, Cys7-Cys37, Cys11Cys23, Cys16-Cys30 and Cys35-Cys39] in such a small 41-residue protein [12]. EAFP2 shows certain homology to

*Address correspondence to this author at the Supercomputer Education and Research Centre, Indian Institute of Science, Bangalore 560 012, India; Tel: +91-80-22933059/22932469/23601409; Fax: +91-80-23600683/23600551;

E-mail: sekar@serc.iisc.ernet.in and sekar@physics.iisc.ernet.in hevein-like antifungal peptides [14], which usually consist of 30-43 amino acid residues cross-linked by three or four disulfide bonds and features a chitin-binding site comprising one serine and three aromatic residues. Such a structural arrangement is conserved in a variety of plant proteins, such as hevein from rubber tree [14], Ac-AMP from Amaranthus caudatus seeds [15], wheat germ agglutinin (WGA) [16] and Urtica dioica agglutinin (UDA) [17]. The antifungal activity of these peptides is assumed to be attributed to their specific chitin-binding activities, since chitin is the main structural component of the fungal cell wall $[18,19]$. The antifungal proteins possess an amphiphilic surface composed of clusters of cationic and hydrophobic residues that are critical for their activity $[20,21]$. In EAFP2, there exists a cationic surface with four positively charged arginine residues (at positions 6 , 9, 36 and 40) that gives rise to an amphiphilic design and in-turn contributes to the inhibitory activity against chitinfree fungi.

EAFP2 is found to exhibit a broad spectrum of antifungal activity against a series of plant pathogens, both chitincontaining and chitin free fungi [12]. The genes encoding several of these antifungal peptides are manipulated to create genetically modified plants with increased fungal resistance [22]. The antifungal effects of EAFP2 are found to be strongly antagonized by calcium ions [23] and it is found to exert inhibitory activity against the opportunistic fungal pathogen, Candida albicans and thus may be used as a novel drug of plant origin for the treatment of candidiasis [24]. The structural characteristics and the conformational dynamics of 


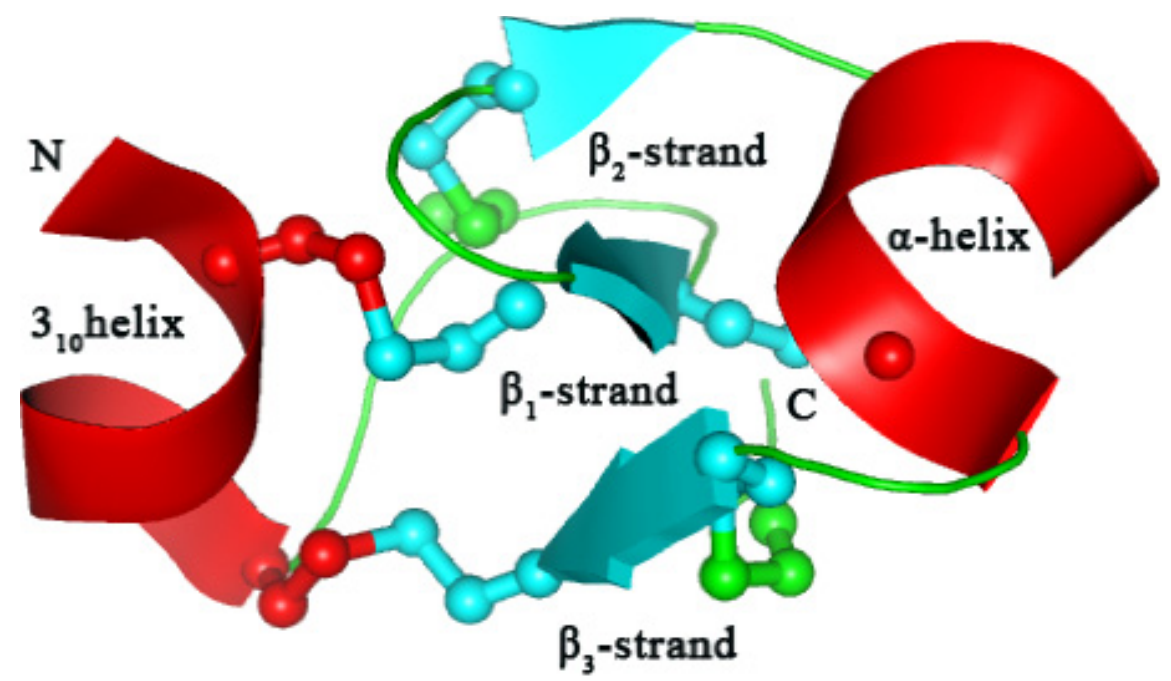

Fig. (1). The ribbon diagram showing the secondary structural elements of EAFP2, created using PyMOL [32].

the mutant structures (cysteine to alanine) of the antifungal protein (EAFP2) have been analyzed to better understand the role of disulfide bonds in maintaining the tertiary structure.

\section{MATERIALS AND METHODS}

\subsection{Molecular Model}

The atomic co-ordinates of the three-dimensional structure [PDB-id: 1P9G] of the cysteine rich antifungal peptide (EAFP2), determined using X-ray crystallography [12], were downloaded from the locally maintained anonymous PDBFTP server (Bioinformatics Centre, Indian Institute of Science, Bangalore, India). The cysteine residues at positions 3, $7,11,16$ and 35 in the native structure were mutated to alanine and the single mutant structures thus obtained were named $\mathrm{C} 3 \mathrm{~A}, \mathrm{C} 7 \mathrm{~A}, \mathrm{C} 11 \mathrm{~A}, \mathrm{C} 16 \mathrm{~A}$ and $\mathrm{C} 35 \mathrm{~A}$ respectively. Each residue in a cysteine pair, forming a disulfide bond, was mutated to alanine to obtain a structure devoid of disulfide bonds and was named mutfive. The in-silico mutants were generated using Swiss-Pdb viewer [25].

\subsection{Molecular Dynamics Simulations}

The molecular dynamics (MD) simulations were carried out using GROMACS v.3.3 [26] with the OPLS-AA/L allatom force field $[27,28]$. A cubic simulation box with the size of $4.3 \times 4.3 \times 4.3 \mathrm{~nm}$ was constructed and the protein models were solvated with the SPC (simple point charge) water model using the genbox program available in the GROMACS suite. In order to counter balance the protein charges, chloride ions were added to the system. Energy minimization was performed using the conjugate-gradient method for 200 ps with the maximum force field cutoff being $1 \mathrm{KJ} \mathrm{mol}^{-1}$. Simulations utilized NPT ensembles with isotropic pressure coupling ( $\mathrm{tp}=0.5 \mathrm{ps}$ ) to $300 \mathrm{~K}$. ParrinelloRahman protocol was used for pressure and Nose-Hoover coupling protocol, was used for temperature. Long range electrostatics were computed using the Particle Mesh Ewald (PME) method [29] and Lennard-Jones energies were cut off at $1.0 \mathrm{~nm}$. Bond lengths were constrained with the LINCS algorithm [30]. Tools available in the GROMACS suite were employed for analysis. The programs GRACE and PyMOL were used to visualize the trajectories [31] and the threedimensional protein structures respectively [32].

\section{RESULTS}

\subsection{Structure and Dynamics of the Native and Mutant Structures: A Comparative Study}

To investigate the effect of cysteine mutations on the three-dimensional structure of EAFP2, molecular dynamics simulations are performed on the native and mutant structures. The change in the conformation during the simulations is monitored by calculating the root mean square deviation (RMSD) from the crystal structure. From Fig. (2) it is observed that the RMSD trajectory of the native structure initially shows fluctuations and then begins to rise after 3500 ps. Such changes in the native structure are expected when a protein is transferred from a solid state to solvent environment [12]. Of all the time averaged single mutant structures obtained after $5 \mathrm{~ns}$ simulations, the C3A structure shows a maximum increase in RMSD before declining towards the end of the simulation. No large fluctuation in RMSD is observed in the C7A structure, when the disulfide bond (Cys7Cys37) connecting the $\mathrm{N}$ and $\mathrm{C}$-terminal segments is disrupted. It is interesting to note that the RMSD trajectory associated with the $\mathrm{C} 35 \mathrm{~A}$ structure remains stable, showing minimal fluctuations. The trajectories of $\mathrm{C} 16 \mathrm{~A}$ and $\mathrm{C} 11 \mathrm{~A}$ structures show small fluctuations before stabilizing towards the end of the simulation. In the case of the time averaged mutfive structure, very large fluctuation in RMSD is observed (Fig. 2).

Fig. (3) shows the root mean square fluctuation (RMSF) of each $\mathrm{C} \alpha$ atom. RMSF is a parameter of residue flexibility about the average structure, which throws light on the dynamic properties of the simulated structures. It is observed that large fluctuations are associated with the residues forming the $\alpha$-helix and $\beta$-turns. The regions forming the $\beta$ strands are subjected to minimal fluctuations and they are more hydrophobic and stable than any other secondary structural elements. Minimal fluctuations are observed in the averaged structure of the single mutant $\mathrm{C} 35 \mathrm{~A}$, compared to the native structure, which corroborates with the RMSD results 


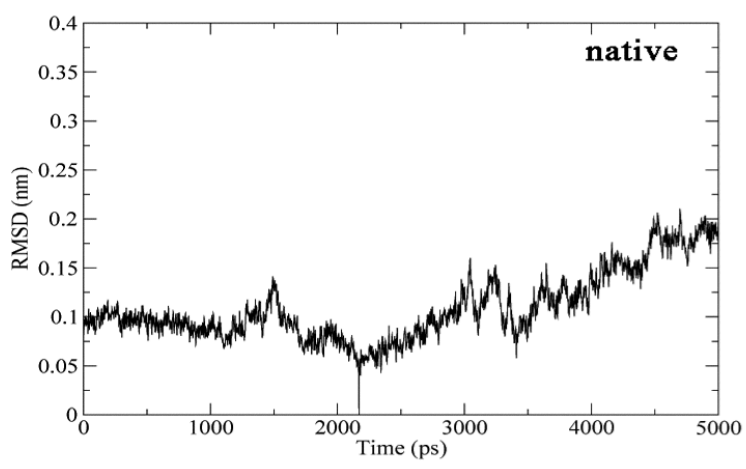

(a)

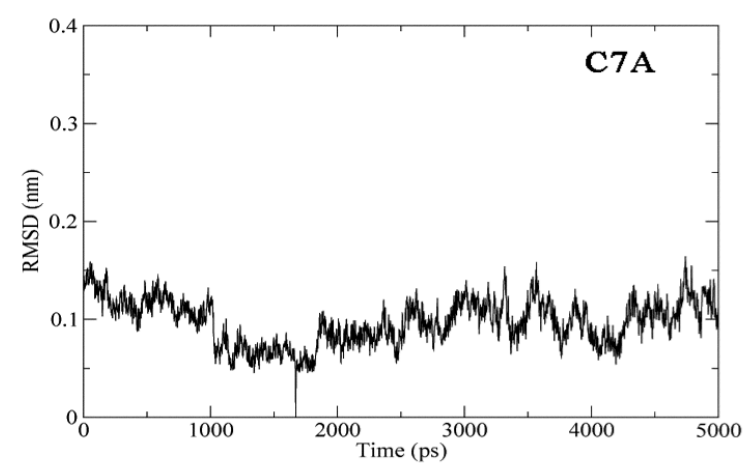

(c)

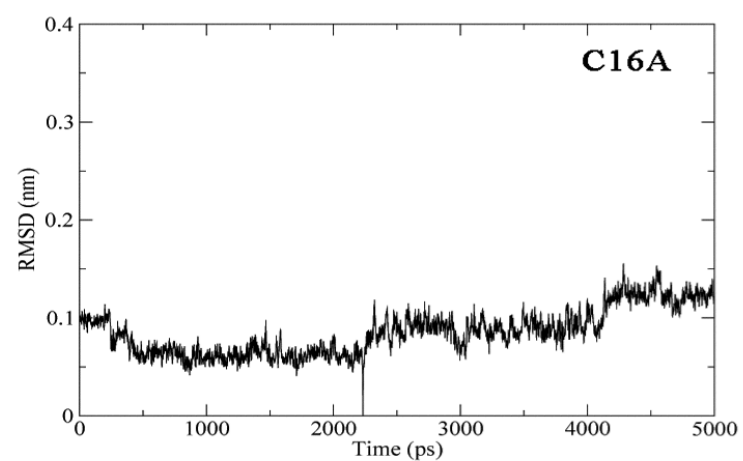

(e)

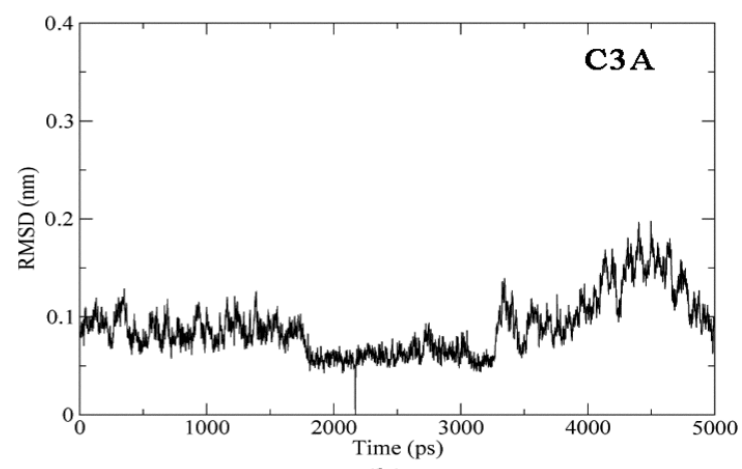

(b)

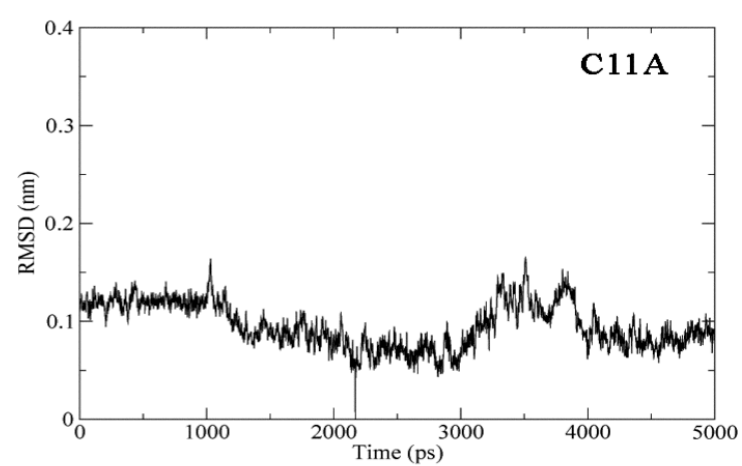

(d)

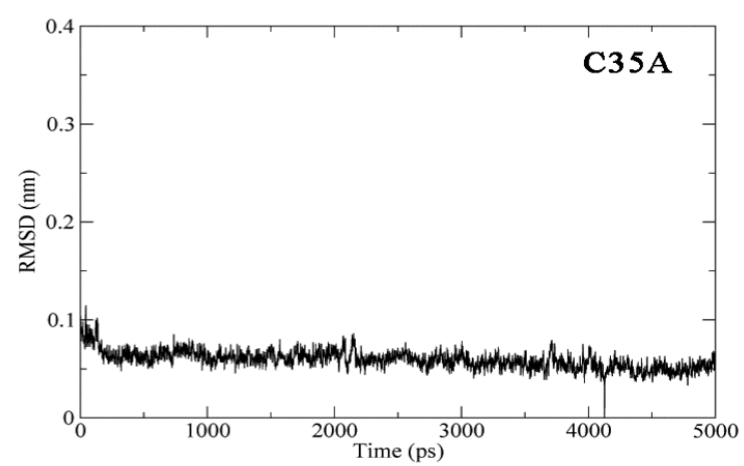

(f)

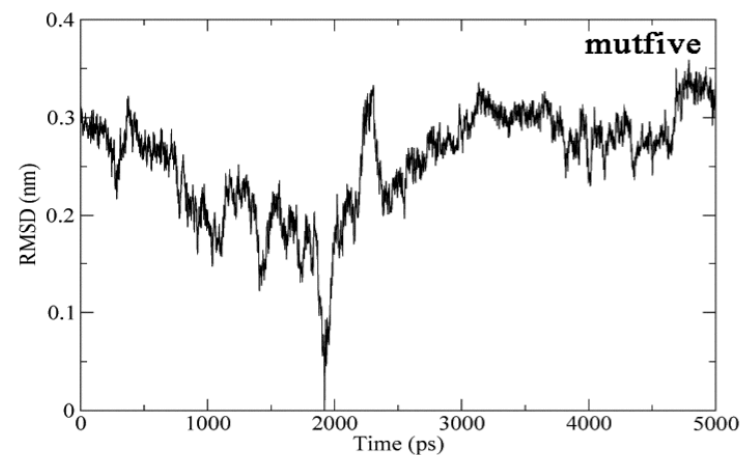

(g)

Fig. (2). The RMS deviations of backbone atoms of native and mutant structures represented as a function of simulation time. Figs. (a), (b), (c), (d), (e), (f) and (g) show deviations associated with native, C3A, C7A, C11A, C16A, C35A and mutfive structures respectively.

shown in Fig. (2). The C7A and mutfive structures, display increased fluctuation in the regions forming the $3_{10}$-helix and $\beta_{1}$-strand. Both these structures lack the additional disulfide bond (Cys 7-Cys37) and hence the $\mathrm{N}$ and $\mathrm{C}$ terminal segments are free in orientation, which results in a change in conformation. In the native structure, the cysteine residues 


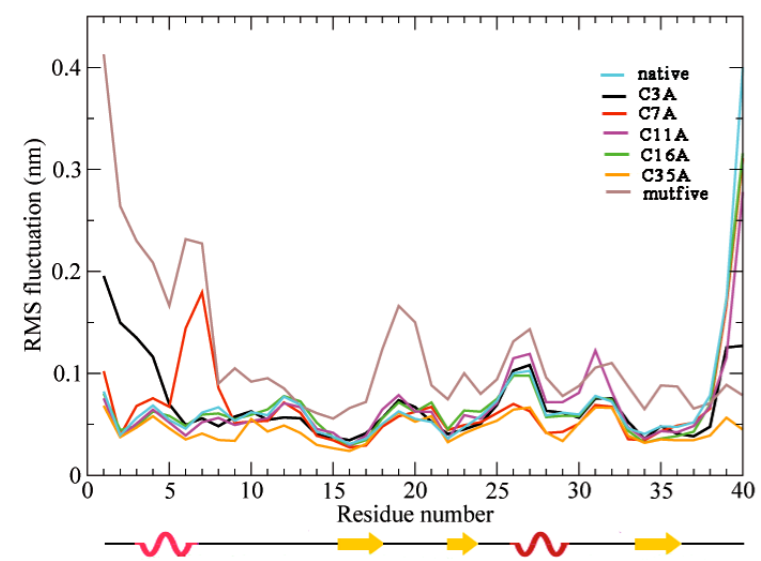

Fig. (3). RMS fluctuations associated with the native and the six mutant structures. are found to be highly stable showing least fluctuation, which indicates that the disulfide bonds formed by these residues are intact and resulted in restricted motions of the cysteine residues. The study of RMSF and RMSD shows that the single point mutations did not result in a drastic conformational change.

\subsection{Analysis of Radius of Gyration $\left(R_{g}\right)$}

Radius of gyration $\left(\mathrm{R}_{\mathrm{g}}\right)$ is a parameter linked to tertiary structural volume of a protein. The $\mathrm{R}_{\mathrm{g}}$ plots of the native and mutant structures shown in Fig. (4) indicate that the mutation of cysteine residues resulted in a slight decrease of $R_{g}$ value during simulations. The $R_{g}$ value of the native structure shows a continuous uptrend, whereas the $R_{g}$ value of the mutant structures increase during the initial stages and then fluctuates before stabilizing towards the end of the simula-
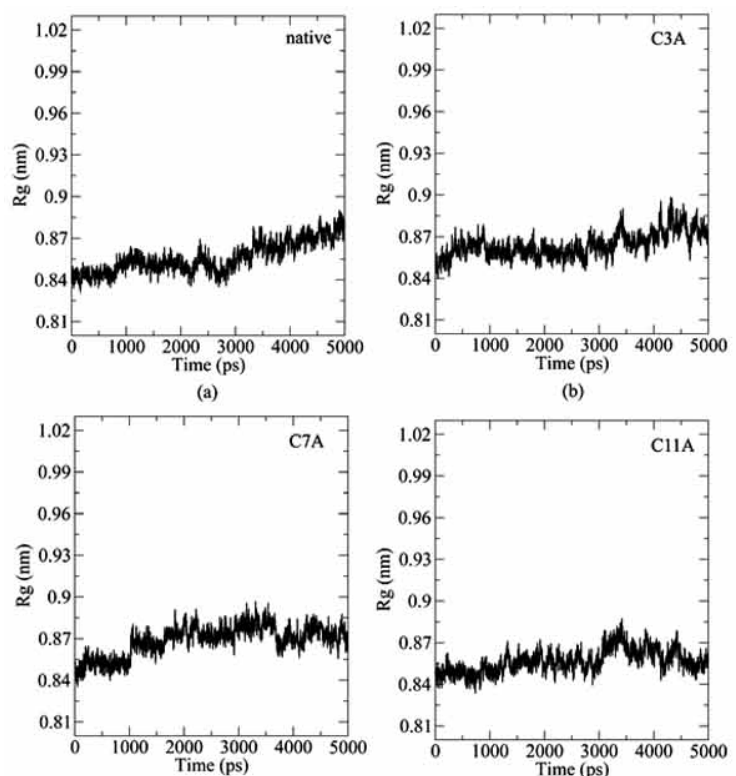

(b)
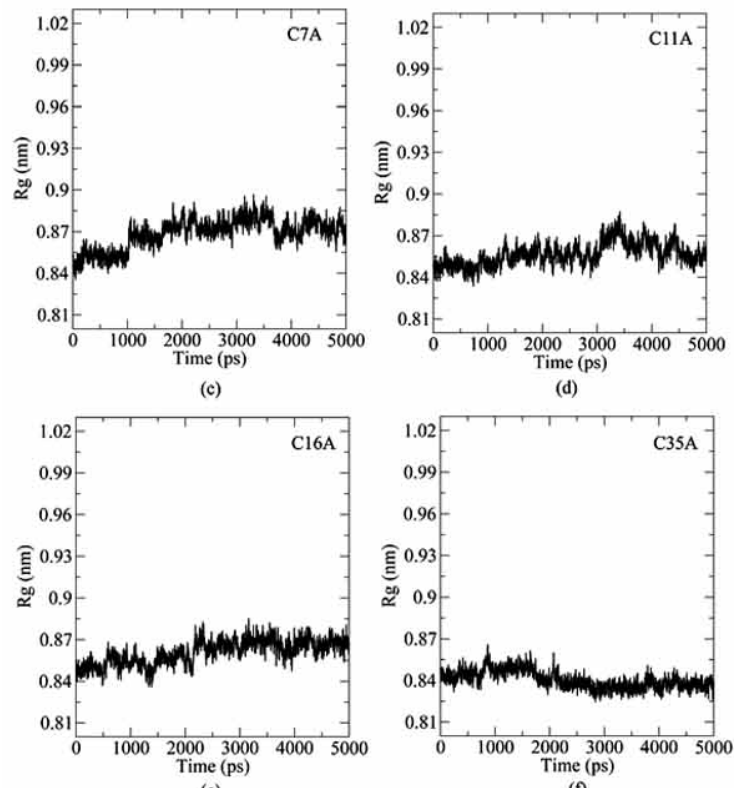

(d)
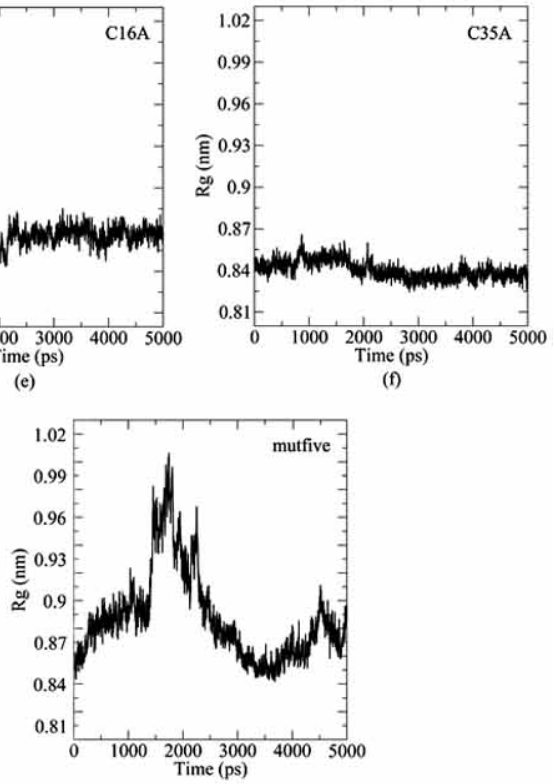

(g)

Fig. (4). The plots showing the radius of gyration $\left(R_{g}\right)$ of native and mutant structures (C3A, C7A, C11A, C16A, C35A and mutfive). 
tion. However, it is interesting to note that in the case of C35A, the $\mathrm{R}_{\mathrm{g}}$ value initially increases and then slumps before stabilizing at around $0.84 \mathrm{~nm}$. The $\mathrm{C} 35 \mathrm{~A}$ structure displays the lowest value of $R_{g}$ compared to the rest of the simulated structures, indicating that the protein is compressed. Furthermore, in the case of mutfive structure, it is observed that the $\mathrm{R}_{\mathrm{g}}$ value increases drastically around $1500 \mathrm{ps}$, shows that the protein expanded dramatically, creating a large amount of void inside and this would have enabled the solvent molecules to penetrate the hydrophobic region. Sparing minor fluctuations associated with the single mutant structures, their $\mathrm{R}_{\mathrm{g}}$ plots are comparable with those obtained for the native structure, which is consistent with the backbone RMSD analysis as shown in Fig. (2).

\subsection{Assessment of Secondary Structures}

Prediction of the secondary structural elements of the time averaged native and mutant structures after $5 \mathrm{~ns}$ simulations is performed using the program STRIDE [33]. The data in Table 1 shows that the conformation of secondary structural elements is affected during the course of simulations. It is observed that the $\alpha$-helix is not preserved in any of the simulated structures, while the $3_{10}$-helix and $\beta_{1}$-strand are not preserved in the C16A, C35A and mutfive structures. Instability of the $\alpha$-helix arises due to the low nucleation probability, which is contributed by the small number of residues forming the helix. However, one may find it interesting to note that the strands $\beta_{2}$ and $\beta_{3}$ are intact in all the time averaged structures. Further, superposition of the crystal and simulated structures performed using $3 \mathrm{dss}$ [34] revealed that the $\beta_{2}$ and $\beta_{3}$-strands are preserved in their respective orientations (data not shown). The time averaged native and mutant structures show a decrease in content of secondary structural elements. Both the native and mutant structures exhibit a tendency to transit from their initial ordered conformation to a random structure composed of coils and turns.

\subsection{Interatomic Distance}

The interatomic distance between $\mathrm{C} \alpha$-atoms of cysteine residues involved in disulfide bond and the residues forming the chitin binding domain (Ser18, Tyr20, 22 and 29) is calculated from the averaged native and mutant structures after 5 ns simulations and the results are summarized in Tables $\mathbf{2}$ and 3 . The variation in the distance among the single mutant structures, compared to the native structure, follows a recognizable pattern. It is observed that maximum variation in distance, associated with each mutant structure, corresponds to a particular mutation it is coupled with. From the results, it is also observed that the variation of distances is very large in the case of mutfive structure. In the case of C35A structure, it is observed that the mutation of cysteine residue did not result in a large change in the interatomic distance. In fact, it is found to be less compared to that of the native structure. A similar observation is also made in the mutfive structure corresponding to Cys35-Cys39. It is interesting to note that the maximum deviation of interatomic distance in C7A and mutfive structure corresponds to the mutation of a cysteine residue involved in a disulfide bond between Cys7 and Cys37. Hence, in such a case, the $\mathrm{N}$ and $\mathrm{C}$ terminal segments adopt a more relaxed conformation, which resulted in an increased interatomic distance. It is observed that
Table 1. Secondary Structural Elements Predicted (STRIDE, [33]) from the Averaged Structure Computed after 5 ns Simulations

\begin{tabular}{|c|c|c|c|c|c|c|c|}
\hline $\begin{array}{l}\text { Amino Acid } \\
\text { Sequence }\end{array}$ & $\begin{array}{l}\text { Na- } \\
\text { tive }\end{array}$ & $\mathrm{C} 3 \mathrm{~A}$ & C7A & C11A & C16A & C35 & Mutfive \\
\hline $\mathrm{T}$ & $\mathrm{C}$ & $\mathrm{C}$ & $\mathrm{C}$ & $\mathrm{C}$ & $\mathrm{T}$ & $\mathrm{T}$ & $\mathrm{T}$ \\
\hline $\mathrm{C}$ & G & $\mathrm{G}$ & G & $\mathrm{C}$ & $\mathrm{T}$ & $\mathrm{T}$ & $\mathrm{T}$ \\
\hline A & $\mathrm{G}$ & $\mathrm{G}$ & $\mathrm{G}$ & G & $\mathrm{T}$ & $\mathrm{T}$ & $\mathrm{T}$ \\
\hline $\mathrm{S}$ & G & G & $\mathrm{G}$ & G & $\mathrm{T}$ & $\mathrm{T}$ & $\mathrm{T}$ \\
\hline $\mathrm{R}$ & $\mathrm{T}$ & $\mathrm{T}$ & $\mathrm{T}$ & $\mathrm{G}$ & $\mathrm{T}$ & $\mathrm{T}$ & $\mathrm{T}$ \\
\hline $\mathrm{C}$ & $\mathrm{T}$ & $\mathrm{T}$ & $\mathrm{T}$ & $\mathrm{T}$ & $\mathrm{T}$ & $\mathrm{T}$ & $\mathrm{T}$ \\
\hline $\mathrm{P}$ & $\mathrm{T}$ & $\mathrm{T}$ & $\mathrm{T}$ & $\mathrm{T}$ & $\mathrm{T}$ & $\mathrm{T}$ & $\mathrm{T}$ \\
\hline $\mathrm{R}$ & $\mathrm{T}$ & $\mathrm{T}$ & $\mathrm{T}$ & $\mathrm{T}$ & $\mathrm{T}$ & $\mathrm{T}$ & $\mathrm{T}$ \\
\hline $\mathrm{P}$ & $\mathrm{T}$ & $\mathrm{T}$ & $\mathrm{T}$ & $\mathrm{T}$ & $\mathrm{T}$ & $\mathrm{T}$ & $\mathrm{T}$ \\
\hline $\mathrm{C}$ & $\mathrm{C}$ & $\mathrm{C}$ & $\mathrm{C}$ & $\mathrm{C}$ & $\mathrm{C}$ & $\mathrm{C}$ & $\mathrm{C}$ \\
\hline $\mathrm{N}$ & $\mathrm{T}$ & $\mathrm{T}$ & $\mathrm{T}$ & $\mathrm{T}$ & $\mathrm{T}$ & $\mathrm{T}$ & $\mathrm{T}$ \\
\hline A & $\mathrm{T}$ & $\mathrm{T}$ & $\mathrm{T}$ & $\mathrm{T}$ & $\mathrm{T}$ & $\mathrm{T}$ & $\mathrm{T}$ \\
\hline $\mathrm{G}$ & $\mathrm{T}$ & $\mathrm{T}$ & $\mathrm{T}$ & $\mathrm{T}$ & $\mathrm{T}$ & $\mathrm{T}$ & $\mathrm{T}$ \\
\hline $\mathrm{L}$ & $\mathrm{T}$ & $\mathrm{T}$ & $\mathrm{T}$ & $\mathrm{T}$ & $\mathrm{T}$ & $\mathrm{T}$ & $\mathrm{T}$ \\
\hline $\mathrm{C}$ & $\mathrm{E}$ & $\mathrm{E}$ & $\mathrm{E}$ & $\mathrm{E}$ & $\mathrm{T}$ & $\mathrm{T}$ & $\mathrm{T}$ \\
\hline $\mathrm{C}$ & $\mathrm{E}$ & E & $\mathrm{E}$ & E & $\mathrm{T}$ & $\mathrm{T}$ & $\mathrm{T}$ \\
\hline $\mathrm{S}$ & E & E & $\mathrm{E}$ & E & $\mathrm{T}$ & $\mathrm{T}$ & $\mathrm{T}$ \\
\hline I & $\mathrm{T}$ & $\mathrm{T}$ & $\mathrm{T}$ & $\mathrm{T}$ & $\mathrm{T}$ & $\mathrm{T}$ & $\mathrm{T}$ \\
\hline $\mathrm{Y}$ & $\mathrm{T}$ & $\mathrm{T}$ & $\mathrm{T}$ & $\mathrm{T}$ & $\mathrm{T}$ & $\mathrm{T}$ & $\mathrm{T}$ \\
\hline G & $\mathrm{T}$ & $\mathrm{T}$ & $\mathrm{T}$ & $\mathrm{T}$ & $\mathrm{T}$ & $\mathrm{T}$ & $\mathrm{T}$ \\
\hline $\mathrm{Y}$ & $\mathrm{C}$ & $\mathrm{C}$ & $\mathrm{C}$ & $\mathrm{C}$ & $\mathrm{E}$ & $\mathrm{E}$ & $\mathrm{C}$ \\
\hline $\mathrm{C}$ & E & $\mathrm{E}$ & $\mathrm{E}$ & $\mathrm{E}$ & $\mathrm{E}$ & $\mathrm{E}$ & $\mathrm{E}$ \\
\hline $\mathrm{G}$ & $\mathrm{E}$ & E & $\mathrm{E}$ & E & $\mathrm{E}$ & $\mathrm{E}$ & $\mathrm{E}$ \\
\hline $\mathrm{S}$ & $\mathrm{C}$ & $\mathrm{C}$ & $\mathrm{C}$ & $\mathrm{C}$ & $\mathrm{C}$ & $\mathrm{C}$ & $\mathrm{C}$ \\
\hline $\mathrm{G}$ & $\mathrm{T}$ & $\mathrm{T}$ & $\mathrm{T}$ & $\mathrm{T}$ & $\mathrm{T}$ & $\mathrm{T}$ & $\mathrm{T}$ \\
\hline A & $\mathrm{T}$ & $\mathrm{T}$ & $\mathrm{T}$ & $\mathrm{T}$ & $\mathrm{T}$ & $\mathrm{T}$ & $\mathrm{T}$ \\
\hline A & $\mathrm{T}$ & $\mathrm{T}$ & $\mathrm{T}$ & $\mathrm{T}$ & $\mathrm{T}$ & $\mathrm{T}$ & $\mathrm{T}$ \\
\hline $\mathrm{Y}$ & $\mathrm{T}$ & $\mathrm{T}$ & $\mathrm{T}$ & $\mathrm{T}$ & $\mathrm{T}$ & $\mathrm{T}$ & $\mathrm{T}$ \\
\hline $\mathrm{C}$ & $\mathrm{T}$ & $\mathrm{T}$ & $\mathrm{T}$ & $\mathrm{T}$ & $\mathrm{T}$ & $\mathrm{T}$ & $\mathrm{T}$ \\
\hline G & $\mathrm{T}$ & $\mathrm{T}$ & $\mathrm{T}$ & $\mathrm{T}$ & $\mathrm{T}$ & $\mathrm{T}$ & $\mathrm{T}$ \\
\hline $\mathrm{A}$ & $\mathrm{T}$ & $\mathrm{T}$ & $\mathrm{T}$ & $\mathrm{T}$ & $\mathrm{T}$ & $\mathrm{T}$ & $\mathrm{T}$ \\
\hline $\mathrm{G}$ & $\mathrm{T}$ & $\mathrm{T}$ & $\mathrm{T}$ & $\mathrm{T}$ & $\mathrm{T}$ & $\mathrm{T}$ & $\mathrm{T}$ \\
\hline $\mathrm{N}$ & $\mathrm{T}$ & $\mathrm{T}$ & $\mathrm{T}$ & $\mathrm{T}$ & $\mathrm{T}$ & $\mathrm{T}$ & $\mathrm{T}$ \\
\hline $\mathrm{C}$ & $\mathrm{E}$ & $\mathrm{E}$ & $\mathrm{E}$ & E & $\mathrm{E}$ & $\mathrm{E}$ & $\mathrm{E}$ \\
\hline $\mathrm{R}$ & $\mathrm{E}$ & $\mathrm{E}$ & $\mathrm{E}$ & $\mathrm{E}$ & $\mathrm{E}$ & $\mathrm{E}$ & $\mathrm{E}$ \\
\hline $\mathrm{C}$ & $\mathrm{E}$ & $\mathrm{E}$ & $\mathrm{E}$ & E & $\mathrm{E}$ & $\mathrm{E}$ & $\mathrm{E}$ \\
\hline $\mathrm{Q}$ & $\mathrm{C}$ & $\mathrm{C}$ & $\mathrm{C}$ & $\mathrm{C}$ & $\mathrm{T}$ & $\mathrm{T}$ & $\mathrm{T}$ \\
\hline C & C & $\mathrm{C}$ & $\mathrm{C}$ & $\mathrm{C}$ & C & C & $\mathrm{C}$ \\
\hline $\mathrm{R}$ & $\mathrm{C}$ & $\mathrm{C}$ & $\mathrm{C}$ & $\mathrm{C}$ & $\mathrm{C}$ & $\mathrm{C}$ & $\mathrm{C}$ \\
\hline $\mathrm{G}$ & $\mathrm{C}$ & C & C & $\mathrm{C}$ & C & C & $\mathrm{C}$ \\
\hline
\end{tabular}

G-3 ${ }_{10}$ Helix; C-Coil; T-Turn; H-Helix and E-Strand. 
Table 2. Disulfide Bonding Pattern and their Relative Interatomic Distance ( $\AA$ ) in the Native and Mutant Structures after 5 ns Simulations

\begin{tabular}{|c|c|c|c|c|c|c|c|}
\hline General Disulfide Bonding Pattern & Native & C3A & C7A & C11A & C16A & C35A & Mutfive \\
\hline \hline Cys3-Cys17 & 5.81 & 7.06 & 5.72 & 6.64 & 6.01 & 5.87 & 9.43 \\
\hline Cys7-Cys37 & 6.11 & 6.10 & 10.23 & 6.05 & 5.39 & 5.88 & 11.34 \\
\hline Cys11-Cys23 & 5.81 & 6.57 & 6.64 & 7.38 & 6.80 & 6.66 & 6.88 \\
\hline Cys16-Cys30 & 5.31 & 5.33 & 5.56 & 5.38 & 5.90 & 5.71 & 5.61 \\
\hline Cys35-Cys39 & 6.04 & 5.97 & 6.64 & 6.28 & 6.43 & 5.49 & 5.97 \\
\hline
\end{tabular}

Table 3. The Relative Interatomic Distance $(\AA)$ between Chitin Binding Residues in the Native and Single Mutant Structures after 5 ns Simulations

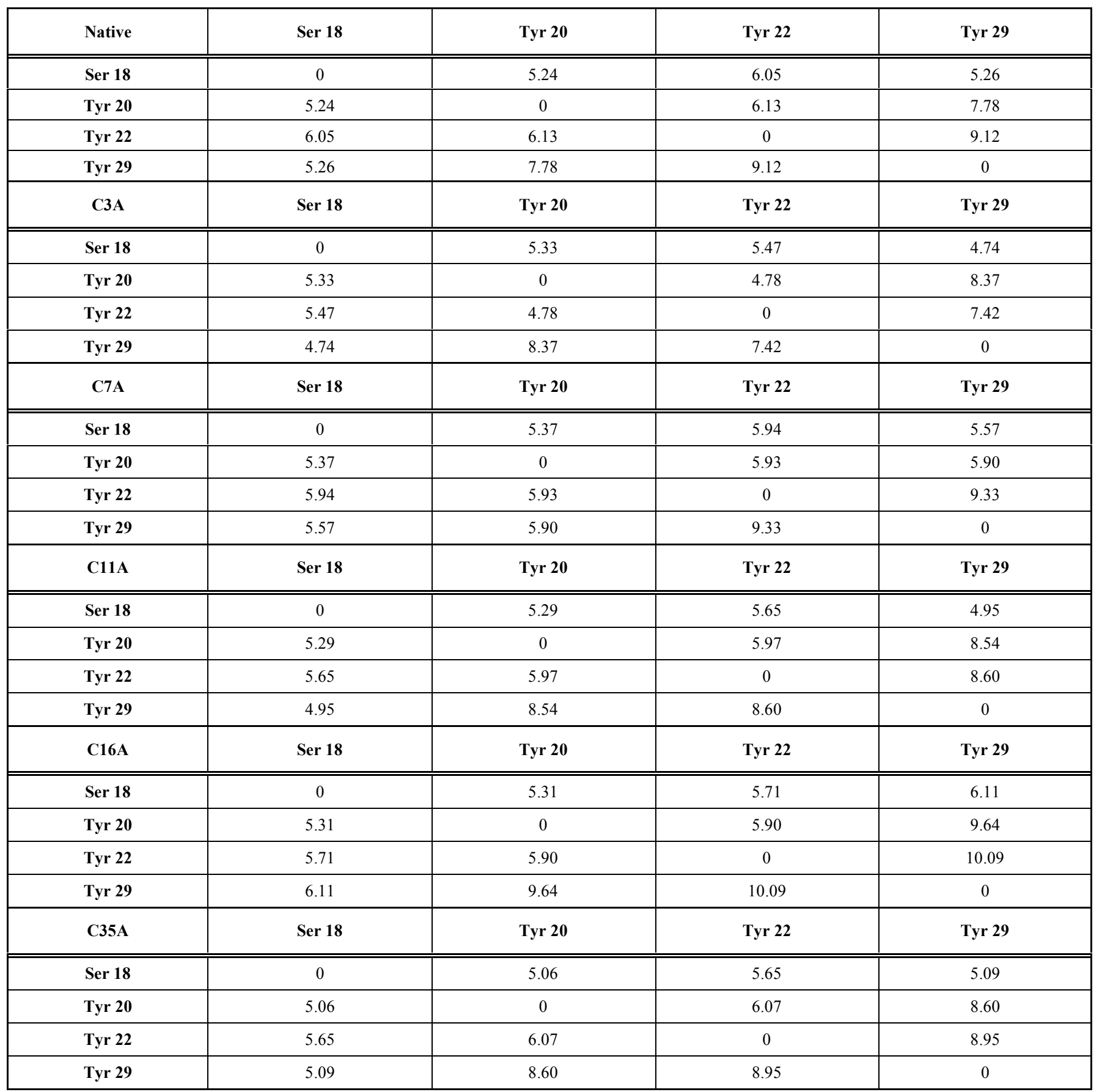


interatomic distance between the residues forming the chitin binding domain is almost comparable $(\sim 1 \AA)$ to those observed in the native structure (Table 3 ). The chitin binding domain tends to be rigid, even when present in mutant structures. However, in C35A structure, the chitin binding domain residues are slightly closer in space compared to the native structure. Some inconsistent data in Table 2 may be attributed to the stochastic nature of the molecular dynamics simulations.

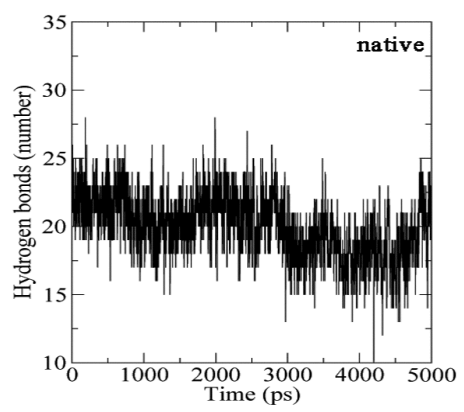

(a)

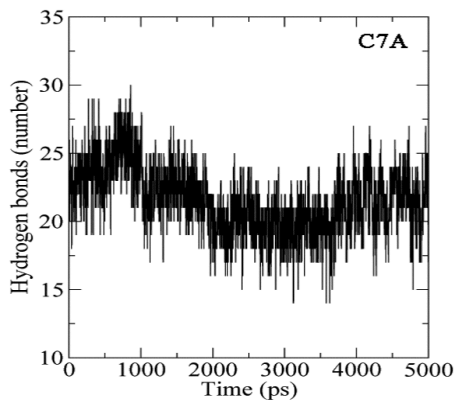

(c)

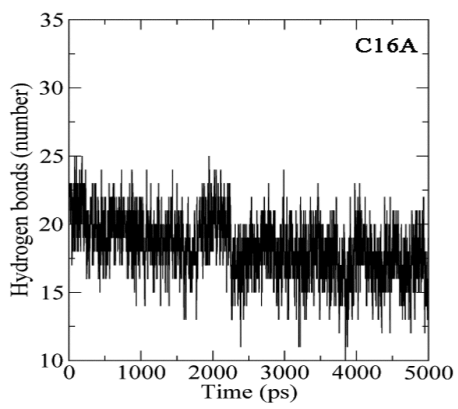

(e)

\subsection{Hydrogen Bonds}

Hydrogen bonds are ubiquitous in protein structures and they help to maintain a stable conformation, hence, hydrogen bond analysis of the native and mutant structures is performed. Fig. (5) provides an insight into the nature of hydrogen bonding pattern observed in the native and mutant structures. It is observed that hydrogen bond number varies between 20 and 25 and is found to be stable in the case of

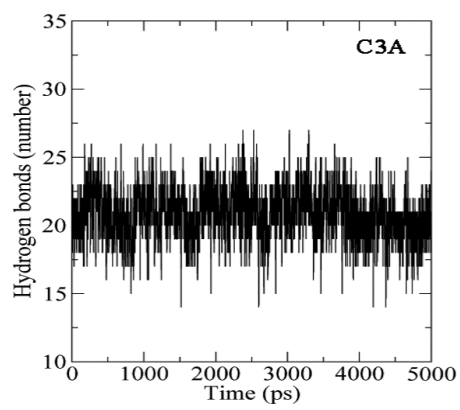

(b)

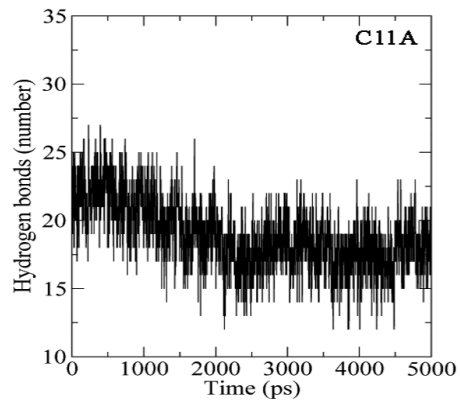

(d)

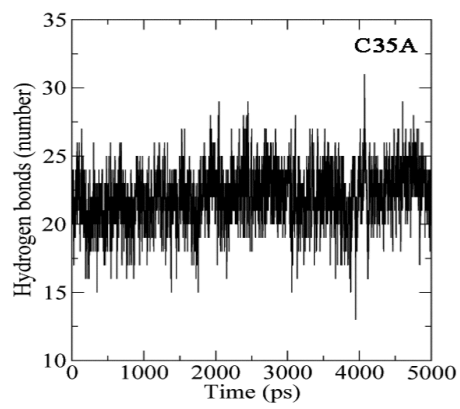

(f)

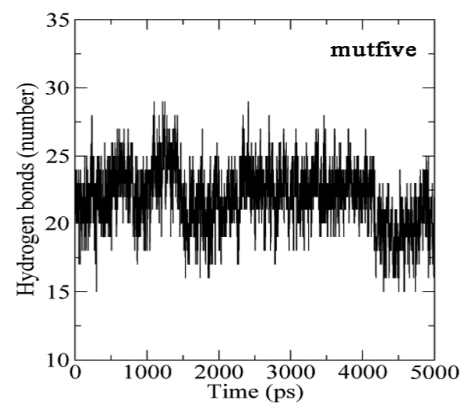

(g)

Fig. (5). Number of hydrogen bonds plotted as a function of simulation time. Figs. (a), (b), (c), (d), (e), (f) and (g) correspond to the native, C3A, C7A, C11A, C16A, C35A and mutfive structures respectively. 
C3A structure, while the large fluctuations associated with the mutfive structure predicts an unstable conformation. The C7A, C11A and C16A structures show a decrease in the number of hydrogen bonds over the simulation time. The comparative analysis of native and $\mathrm{C} 35 \mathrm{~A}$ structure reveals that the latter has a more stable trajectory. It appears though that the loss of disulfide bond (Cys35 and Cys39) actually results in a tertiary structure conformation, which is more favorable for forming and maintaining hydrogen bond contacts. Hence, a structure with increased stability and lesser volume is obtained.

\subsection{Accessible Surface Area}

In order to discern the effect of cysteine mutations on the conformational change of EAFP2, the solvent accessible surface area (ASA) is calculated for both the native and mutant structures (Fig. 6). It is observed that there is a significant decrease in solvent accessibility values of C35A structure, which is in good agreement with previous conclusions about the reduced volume of C35A structure compared to native and other mutant structures. The $\mathrm{C} 3 \mathrm{~A}$ structure shows a continuous increase in accessible surface area

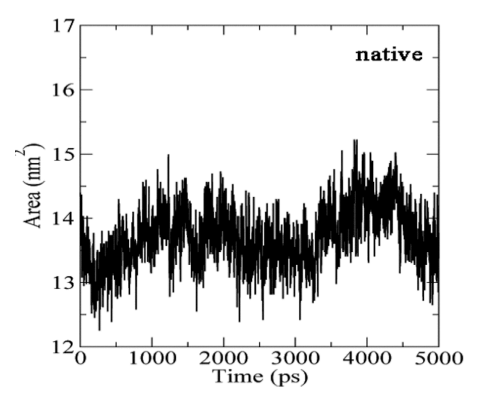

(a)

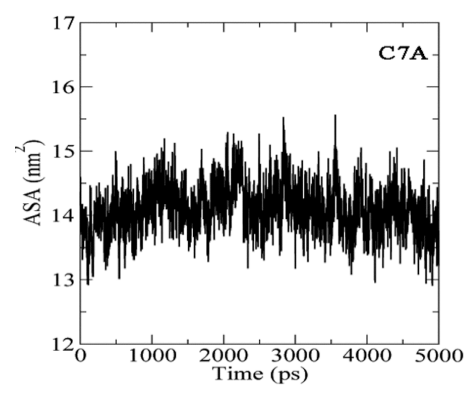

(c)

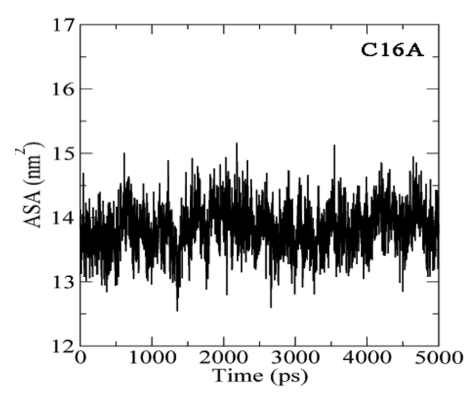

(e)

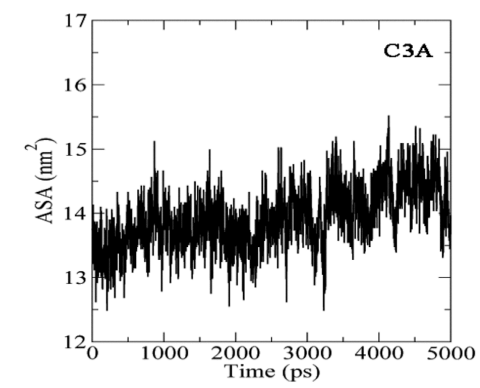

(b)

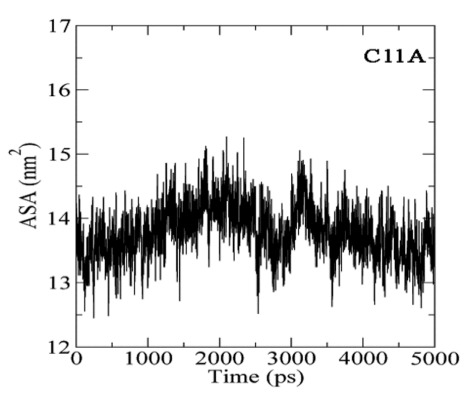

(d)

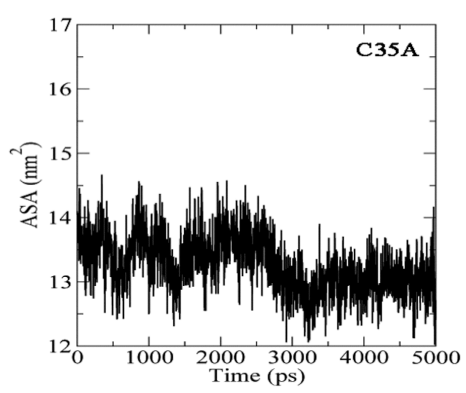

(f)

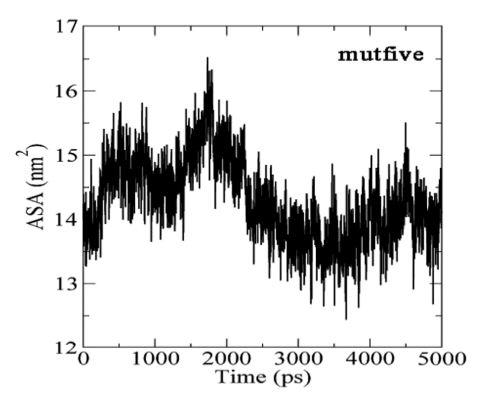

(g)

Fig. (6). Accessible surface area (ASA) of the native and mutant structures plotted as a function of simulation time. Figs. (a), (b), (c), (d), (e), (f) and (g) show changes associated with native, C3A, C7A, C11A, C16A, C35A and mutfive structures respectively. 
values. The increase in solvent accessibility of the hydrophobic buried residues makes them more mobile. As a result of the increased solvent exposure, the protein surface becomes more hydrophobic than in the native state. In the case of mutfive structure, large fluctuations in the accessible surface area are observed. The structure may become unstable due to change in intra-molecular hydrophobic contacts. It is also observed that the results obtained from solvent accessibility analysis are consistent with the results obtained from the analysis of radius of gyration.

\section{DISCUSSION}

The comparison of RMSDs of the time averaged native and mutant structures reveal the simulation trajectory of the C35A structure to be the lowest and it does not display any significant fluctuations (Fig. 2). A similar case is also observed on the analysis of its RMSF. The disulfide bond absent in the C35A structure actually connects $\beta_{3}$-strand to a $\beta$-turn (extending from Gly31 to Asn34). Somehow, the single point mutation results in a more compact structure and this conclusion is further validated by results obtained from the analysis of radius of gyration, accessible surface area and the number of hydrogen bonds. The results show the C35A structure to be more compact compared to the native structure. A similar trend is also observed in the case of human neuroglobin [35].

In the native structure, the disulfide bond (Cys7-Cys37) plays an important role in maintaining the tertiary structure conformation, as it connects the $\mathrm{N}$ and C-terminal segments creating a cationic surface [12], which is critical for the antimicrobial activity. The cationic surface binds to the negatively charged phospholipid of the microbial cell membrane [36]. However, in the case of C7A structure, the cationic surface cannot form and hence, loss of antifungal activity against chitin free fungi may arise. The loss of Cys7-Cys37 bond also results in increased interatomic distance (Table 2). The effect of single point mutation (C7A) on the antifungal activity against both chitin containing and chitin free fungi needs to be experimentally validated. The continuous increase of solvent accessible surface area trajectory of the C3A structure can be explained by the fact that it lacks the disulfide bond, which is required to shield the $3_{10}$-helix from the solvent molecules. Further, the C3A structure also displays a tendency to maintain hydrogen bond contacts throughout the simulation. Thus, loss of the disulfide bond (Cys3-Cys17) does not result in a large conformation change. In the $\mathrm{C} 16 \mathrm{~A}$ structure, the disulfide bond linking the $\beta_{1}$-strand and $\alpha$-helix is absent and its RMSD trajectory shows minor fluctuations and hovers around $0.1 \mathrm{~nm}$. The $\mathrm{R}_{\mathrm{g}}$ and solvent accessibility studies performed on the C16A structure, show that there is no significant change in conformation and it appears that the Cys3-Cys17 bond sufficiently compensates for the loss the Cys16-Cys30 bond.

The shifts in RMSF obtained for native and mutant structures are as a result of the presence of a large number of $\beta$ turns and the unstable nature of the $\alpha$-helix and $\beta_{1}$-strand. The increased fluctuation in RMSF exhibited by the mutant structures is also due to the initial change made in the conformation of these structures. The mutfive structure exhibits a large change in RMSD, radius of gyration and accessible surface area values, indicating significant loss of ordered conformation. Thus, the loss of all five disulfide bonds severely affects the tertiary structure conformation. A significant decrease in the content of secondary structural elements is observed in both the native and mutant structures. The simulated structures are found to be more prone to adopt a random coil conformation from a more ordered structure (Table 1). Further, the unstable nature of $\alpha$-helix and $\beta_{1^{-}}$ strand contribute to increased peptide flexibility. Only the $\beta_{2}$ and $\beta_{3}$-strands are preserved in all the simulated structures, which corroborates with the experimental evidence that sheets are more stable than helices [37]. The study of interatomic distances between residues forming the chitin binding domain (Table 3) show the chitin binding domain is relatively rigid.

\section{CONCLUSION}

The present study elucidates the effect of disulfide bonds on the tertiary structure and throws light on the conformational dynamics of the native and mutant structures. It is identified that single point mutation of a cysteine residue did not cause a large change in the conformation of the tertiary structure. However, in the C7A structure, a large change of interatomic distance is observed and this may result in possible loss of antifungal activity. A significant decrease of ordered conformation is observed in the case of mutfive structure. Further, it is found that the single point mutation in C35A structure actually resulted in a more compact threedimensional structure. The effect of mutation of Cys35 residue on the antifungal activity needs to be experimentally verified. In addition, our findings can be utilized to develop more stable drugs against candidiasis and plant pathogens. A similar work in other cysteine-rich antifungal proteins is in progress.

\section{ACKNOWLEDGEMENTS}

The work reported in the manuscript is fully supported by the Department of Biotechnology (DBT), Government of India. The authors gratefully acknowledge the facilities at the Supercomputer Education and Research centre, the Interactive Graphics Based Molecular Modelling (IGBMM) and Distributed Information Centre (DIC).

\section{REFERENCES}

[1] Wedemeyer WJ, Welker E, Narayan M, Scheraga HA. Disulfide bonds and protein folding. Biochemistry 2000; 39: 4207-16.

[2] Narayan M, Welker E, Wedemeyer WJ, Scheraga HA. Oxidative folding of proteins. Acc Chem Res 2000; 33: 805-12.

[3] Kadokura H, Katzen F, Beckwith J. Protein disulfide bond formation in prokaryotes. Annu Rev Biochem 2003; 72: 111-35.

[4] Hogg PJ. Disulfide bonds as switches for protein function. Trends Biochem Sci 2003; 28: 210-4.

[5] Matsumura M, Signor G, Matthews BW. Substantial increase of protein stability by multiple disulphide bonds. Nature 1989; 342: 291-3.

[6] Mas JM, Aloy P, Marti-Renom MA, et al. Classification of protein disulphide-bridge topologies. J Comput Aided Mol Des 2001; 15: 477-87.

[7] Harvey AL. Toxins ' $R$ ' Us: more pharmacological tools from nature's superstore. Trends Pharmacol Sci 2002; 23: 201-3.

[8] Harvey AL, Bradley KN, Cochran SA, et al. What can toxins tell us for drug discovery? Toxicon 1998; 36: 1635-40.

[9] Betz SF. Disulfide bonds and the stability of globular proteins. Protein Sci 1993; 2: 1551-8.

[10] Moghaddam ME, Naderi-Manesh H. Role of disulfide bonds in modulating internal motions of proteins to tune their function: 
molecular dynamics simulation of scorpion toxin Lqh III. Proteins 2006; 63: 188-96.

[11] Tidor B, Karplus M. The contribution of cross-links to protein stability: a normal mode analysis of the configurational entropy of the native state. Proteins 1993; 15: 71-9.

[12] Xiang Y, Huang RH, Liu XZ, Ying Z, Wang DC. Crystal structure of a novel antifungal protein distinct with five disulfide bridges from Eucommia ulmoides oliver at an atomic resolution. J Struct Biol 2004; 148: 86-97.

[13] Huang RH, Xiang Y, Tu GZ, Zhang Y, Wang DC. Solution structure of eucommia antifungal peptide: a novel structural model distinct with a five-disulfide motif. Biochemistry 2004; 43 (20): 600512.

[14] Andersen NH, Cao B, Romero AR, Arreguin B. Hevein: NMR assignment and assessment of solution-state folding for the agglutinin-toxin motif. Biochemistry 1993; 32: 1407-22.

[15] Martins JC, Maes D, Loris R, et al. H NMR study of the solution structure of Ac-AMP2, a sugar binding antimicrobial protein isolated from Amaranthus caudatus. J Mol Biol 1996; 258: 322-33.

[16] Harata K, Nagahora H, Jigami Y. X-ray structure of wheat germ agglutinin isolectin 3. Acta Cryst 1995; D 51: 1013-9.

[17] Harata K, Muraki M. Crystal structures of Urtica dioica agglutinin and its complex with tri-N-acetylchitotriose. J Mol Biol 2000; 297: 673-81.

[18] Broekaert WF, Van Parijs J, Leyns F, Joos K, Peumans WJ. A chitin-binding lectin from stinging nettle rhizomes with antifungal properties. Science 1989; 245: 1100-2.

[19] Raikhel NV, Lee HI, Broekaert WF. Structure and function of chitin-binding proteins. Annu Rev Plant Physiol Plant Mol Biol 1993; 44: 591-615.

[20] Hwang PM, Vogel HJ. Structure-function relationships of antimicrobial peptides. Biochem Cell Biol 1998; 76: 235-46.

[21] Zasloff M. Antimicrobial peptides of multicellular organisms. Nature 2002; 415: 389-95.

[22] Selitrennikoff CP. Antifungal proteins. Appl Environ Microbiol 2001; 67: 2883-94.

[23] Huang RH, Xiang Y, Liu XZ, Zhang Y, Hu Z, Wang DC. Two novel antifungal peptides distinct with a five-disulfide motif from the bark of Eucommia ulmoides oliver. FEBS Lett 2002; 521: 8790.
[24] Liu S, Zhao D, Yuzhen Han. An antifungal peptide from the bark of Eucommia ulmoides oliv. effective against Candida albicans in vitro. Int Symp Eucommia ulmoides 2002; 1: 78-81.

[25] Guex N, Peitsch MC. Swiss-model and the swiss-pdbviewer: an environment for comparative protein modeling. Electrophoresis 1997; 18: 2714-23.

[26] Spoel DVD, Lindahl E, Hess B, Groenhof G, Mark AE, Berendsen HJ. GROMACS: fast, flexible, and free. J Comput Chem 2005; 26 : 1701-18.

[27] Jorgensen WL, Maxwell DS, Tirado-Rives J. Development and testing of the OPLS all-atom force field on conformational energetics and properties of organic liquids. J Am Chem Soc 1996; 118(45): 11225-36.

[28] Kaminski GA, Friesner RA, Tirado-Rives J, Jorgensen WL. Evaluation and reparametrization of the OPLS-AA force field for proteins via comparison with accurate quantum chemical calculations on peptides. J Phys Chem 2001; 105: 6474-87.

[29] Darden TD, York PL. Particle mesh Ewald: an $N \cdot \log (N)$ method for Ewald sums in large systems. J Chem Phys 1993; 98: 10089-92.

[30] Hess B, Bekker H, Berendsen HJC, Fraaije JGEM. LINCS: a linear constraint solver for molecular simulations. J Comput Chem 1997; 18: 11225-36.

[31] Grace [homepage on the Internet]. C1998-2000 [cited 2008 Oct] Available from: http://plasma-gate.weizmann.ac.il/Grace/

[32] Delano WL. The PyMOL Molecular Graphics System. Delano Scientific: Palo Alto, CA, USA 2002.

[33] Heinig M, Frishman D. STRIDE: a web server for secondary structure assignment from known atomic coordinates of proteins. Nucleic Acids Res 2004; 32: W500-2.

[34] Sumathi K, Ananthalakshmi P, Md Roshan MNA, Sekar K. 3dss: 3 dimensional structural superposition. Nucl Acids Res 2006; 34: W128-34.

[35] Ishikawa H, Kim S, Kwak K, Wakasugi K, Fayer MD. Disulfide bond influence on protein structural dynamics probed with 2D-IR vibrational echo spectroscopy. Proc Natl Acad Sci USA 2007; 104: 19309-14.

[36] Hwang PM, Vogel HJ. Structure function relationships of antifungal peptides. Biochem Cell Biol 1998; 76: 235-46.

[37] Perczel A, Jakli I, Csizmadia I. Intrinsically stable secondary structure elements of proteins: a comprehensive study of folding units of proteins by computation and by analysis of data determined by Xray crystallography. Chemistry 2003; 9: 5332-42.

(C) Jayanthi et al.; Licensee Bentham Open.

This is an open access article licensed under the terms of the Creative Commons Attribution Non-Commercial License (http://creativecommons.org/licenses/by$\mathrm{nc} / 3.0 /$ ), which permits unrestricted, non-commercial use, distribution and reproduction in any medium, provided the work is properly cited. 